\title{
A CONSTRUÇÃO DA DINÂMICA TEMPORAL NO JORNALISMO: ANÁLISE DO EMPREGO DAS FORMAS VERBAIS EM SEQUÊNCIAS NARRATIVAS DE REPORTAGENS
}

\author{
Gustavo Ximenes Cunha* \\ Universidade Federal de Alfenas \\ Alfenas, Minas Gerais, Brasil
}

\begin{abstract}
Resumo: Este trabalho apresenta parte dos resultados da pesquisa desenvolvida em Cunha (2013), a fim de evidenciar como os jornalistas utilizam as formas verbais para construir a dinâmica temporal em sequências narrativas no interior de reportagens. Para proceder a um estudo adequado das formas verbais do português, a pesquisa buscou na proposta de Fiorin (2010, 2011) instrumentos de análise para estudar as regularidades e as especificidades das formas verbais utilizadas nas 53 sequências narrativas do corpus. A análise permitiu constatar a complexidade da maneira como os jornalistas usam as formas verbais para expressar a dinâmica temporal dos acontecimentos, bem como a profunda relação que se estabelece entre o emprego das formas verbais e o gênero do discurso.
\end{abstract}

Palavras-chave: Sequência narrativa. Forma verbal. Reportagem.

\section{INTRODUÇÃO}

Apresentando parte dos resultados alcançados na pesquisa desenvolvida em Cunha (2013), este trabalho busca evidenciar como os jornalistas utilizam as formas verbais do indicativo para construir a dinâmica temporal em sequências narrativas no interior de reportagens.

A pesquisa mencionada partiu da hipótese de que as noções de gênero do discurso e de tipo de discurso são de tal forma imbricadas que cada gênero possui tipos específicos. Com base nessa hipótese, investiguei como se caracteriza o tipo narrativo do gênero reportagem e como esse tipo se atualiza na construção de sequências narrativas extraídas de exemplares desse gênero. Essa investigação se baseou na análise de um corpus constituído por dezesseis reportagens publicadas nas edições de janeiro de 2010 das revistas semanais de informação Carta Capital, Época, IstoÉ e Veja.

Compreender de maneira aprofundada o modo como se narra em reportagens implicou a consideração de um conjunto amplo de informações situacionais, textuais e linguísticas. Por isso, a pesquisa desenvolvida em Cunha (2013) apoiou-se nos postulados teóricos e metodológicos do Modelo de Análise Modular do Discurso. O modelo modular é uma abordagem para o estudo da complexidade do discurso. Em linhas bastante gerais, para esse modelo, o discurso resulta da inter-relação de informações provenientes de três dimensões: linguística, textual e situacional. Cada dimensão compreende módulos responsáveis pela descrição de subdomínios do discurso. Assim, a dimensão linguística se constitui dos módulos lexical e sintático; a

\footnotetext{
* Doutor em Linguística pela Universidade Federal de Minas Gerais. Professor Adjunto da UNIFAL-MG. Email: ximenescunha@yahoo.com.br 
dimensão textual, do modulo hierárquico; e a dimensão situacional, dos módulos interacional e referencial. Na produção e na compreensão do discurso, as informações modulares se combinam em formas de organização, tais como a relacional, a sequencial, a enunciativa, a composicional, a tópica e a estratégica ${ }^{1}$.

A pesquisa se fez em três etapas, que correspondem às análises das formas de organização sequencial, composicional e estratégica. Neste trabalho, exponho um conjunto de resultados alcançados na segunda etapa da pesquisa, a que estudou a forma de organização composicional do discurso. Essa etapa investigou uma série extensa de propriedades textuais e linguísticas típicas de um total de 53 sequências narrativas das reportagens do corpus, sequências que haviam sido identificadas na primeira etapa. Algumas das propriedades estudadas foram o emprego das formas verbais, as relações de discurso e sua marcação por conectores, a construção da cadeia referencial e o uso das formas de discurso representado. Este trabalho se dedica à apresentação e à discussão do modo como os jornalistas utilizam as formas verbais para criar as diferentes perspectivas temporais dos acontecimentos que narram.

Para proceder a um estudo adequado das formas verbais do português empregadas em sequências narrativas de reportagens, a pesquisa explorou a concepção modular do modelo teórico e metodológico em que se fundamenta e buscou na proposta de Fiorin $(2010,2011)$ instrumentos de análise para estudar as regularidades e as especificidades do emprego das formas verbais nas sequências.

A escolha da proposta de Fiorin para o estudo das formas verbais empregadas em sequências narrativas de reportagens encontra três justificativas. Em primeiro lugar, nos trabalhos sobre a forma de organização composicional (FILLIETTAZ, 1999; FILLIETTAZ; GROBET, 1999; ROULET; FILLIETTAZ; GROBET, 2001), não se realizou um estudo sistemático das formas verbais. Para o estudo dessas formas, mostrou-se, então, necessária a busca por referencial teórico externo ao modelo. Em segundo lugar, a proposta de Fiorin é uma abordagem da Análise do Discurso, que toma como ponto de partida, desenvolvendo, a proposta de Benveniste, o que a torna compatível com as postulações mais gerais do modelo modular (ROULET; FILLIETTAZ; GROBET, 2001). Por fim, mas não menos importante, é uma proposta pensada e elaborada para dar conta das especificidades do sistema verbal do português, que, como veremos adiante, apresenta, por exemplo, apenas uma forma verbal, o pretérito perfeito simples, para realizar as funções do passé simple e do passé composé, formas verbais do francês.

Assim, este trabalho se inicia com uma apresentação sucinta dessa proposta. Em seguida, expõe e discute os resultados da análise das 53 sequências narrativas.

\section{SISTEMA VERBAL DO PORTUGUÊS}

Desenvolvendo postulações de Benveniste, a proposta elaborada por Fiorin procura verificar os mecanismos pelos quais as categorias de pessoa, espaço e tempo se projetam no discurso. Por ser essa uma proposta bastante ampla, cuja apresentação

\footnotetext{
${ }^{1}$ Para esclarecimentos sobre o Modelo de Análise Modular do Discurso, ver Roulet, Filliettaz e Grobet (2001), Marinho (2004), Cunha (2012, 2013) e Marinho e Cunha (2014). 
detalhada foge aos objetivos deste trabalho, neste item trato apenas do modo como Fiorin estuda a categoria de tempo, focalizando em especial como o sistema temporal do português organiza os tempos verbais e como estes se projetam no discurso.

Para Fiorin (2010, p. 144), o tempo linguístico se distingue de outras noções de tempo (crônico, físico) pelo fato de que aquele "se organiza em relação ao momento da enunciação", sendo, portanto, gerado no discurso: "O discurso instaura um agora, momento da enunciação. Em contraposição ao agora, cria-se um então. Esse agora é, pois, o fundamento das oposições temporais da língua" (FIORIN, 2010, p. 142). Como eixo organizador do sistema temporal da língua, esse agora faz surgir um antes e um depois. Por isso, o autor aplica ao momento da enunciação a categoria topológica concomitância vs não-concomitância (anterioridade vs posterioridade), obtendo três momentos de referência: presente, pretérito e futuro em relação ao momento da enunciação.

A aplicação dessa categoria topológica ao momento da enunciação permite dar conta do fato de que existem na língua dois sistemas temporais distintos. O primeiro se relaciona ao momento da enunciação, porque expressa coincidência entre esse momento e o momento de referência presente. $O$ segundo se relaciona a um momento de referência instalado no enunciado e expressa que esse momento e o da enunciação não são coincidentes, podendo o momento de referência ser anterior (pretérito) ou posterior (futuro) em relação ao da enunciação. Fiorin distingue esses dois sistemas, denominando o primeiro de enunciativo e o segundo de enuncivo.

No discurso, as informações ou os diferentes acontecimentos expressos (estados e transformações) se organizam em relação aos três momentos de referência: o presente, o pretérito e o futuro. Para entender como ocorre essa organização, aplica-se a mesma categoria topológica concomitância vs não-concomitância (anterioridade vs posterioridade) a cada um dos momentos de referência. Essa aplicação permite ao autor explicitar que, em relação ao momento de referência, o momento do acontecimento pode ser concomitante ou não-concomitante. Se for não-concomitante, o momento do acontecimento pode ser anterior ou posterior em relação ao momento de referência. Fiorin (2010, p. 146) representa os sistemas temporais linguísticos por meio da figura 1, mais adiante: ${ }^{2}$

No português, existem tempos verbais especializados em expressar a anterioridade, a concomitância e a posterioridade dos acontecimentos em relação a cada um dos momentos de referência. Apresento a seguir os tempos verbais integrantes de cada sistema ${ }^{3}$ :

\footnotetext{
${ }^{2}$ Momento da enunciação (ME); momento da referência (MR); momento do acontecimento (MA).

${ }^{3}$ Neste trabalho, estudo apenas os tempos verbais do indicativo. Essa escolha se deve ao fato de que os tempos do subjuntivo, ao contrário dos do indicativo, não se distribuem entre os sistemas enunciativo e enuncivo. Como mostra Fiorin (2010, p. 183-190), a função dos tempos do subjuntivo, quando ocorrem em orações subordinadas, é indicar a concomitância, a anterioridade ou a posterioridade do acontecimento que expressa em relação ao marco temporal constituído, principalmente, pelo verbo da oração principal, independentemente de ser enunciativo ou enuncivo o tempo desse verbo. Além disso, o mesmo tempo verbal do subjuntivo pode expressar concomitância, anterioridade ou posterioridade, dependendo do tempo do verbo (enunciativo ou enuncivo) da oração principal. Como o estudo dessas especificidades do modo subjuntivo extrapola os limites deste trabalho e como nas sequências narrativas estudadas os tempos verbais do indicativo são bem mais frequentes do que os do subjuntivo, optei por estudar apenas os tempos do indicativo.
} 


\section{Sistema enunciativo}

- Momento de referência presente:

- concomitância: presente;

- anterioridade: pretérito perfeito 1 ;

- posterioridade: futuro do presente.

\section{Sistema enuncivo}

- Momento de referência pretérito:

- concomitância: pretérito perfeito 2 e pretérito imperfeito;

- anterioridade: pretérito mais-que-perfeito simples e composto;

- posterioridade: futuro do pretérito simples e composto.

- Momento de referência futuro:

- concomitância: futuro do presente simples e progressivo (estarei + gerúndio);

- anterioridade: futuro anterior (futuro do presente composto);

- posterioridade: futuro do pretérito simples.

\section{Figura 1 - Sistemas temporais linguísticos}

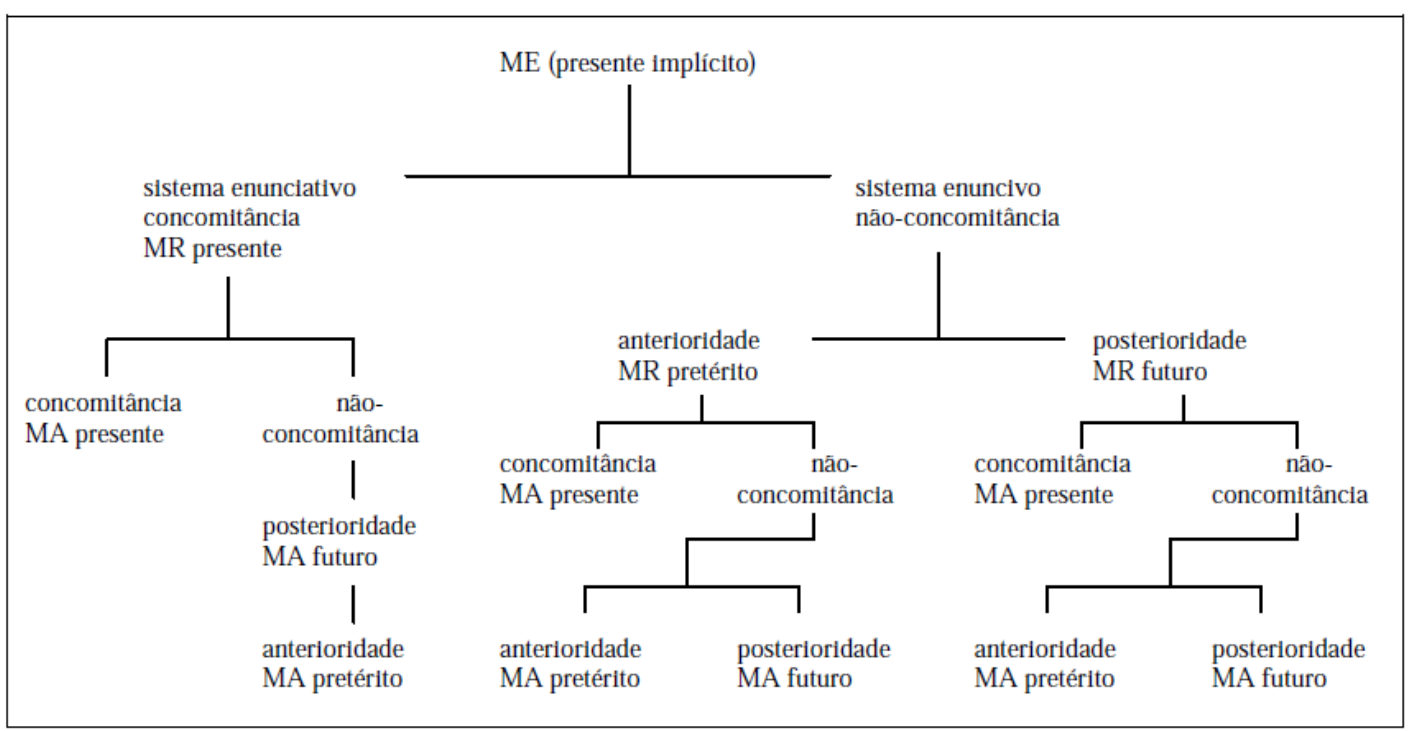

Fonte: Fiorin (2010, p. 146)

Conforme Fiorin, caso o momento de referência seja presente, utilizam-se os tempos verbais do sistema enunciativo, ocorrendo o que o autor conceitua como "debreagem temporal enunciativa". Nesse caso, a concomitância, a anterioridade e a posterioridade dos acontecimentos terão como baliza o momento da enunciação. Por isso, o momento de referência presente só é explicitado em circunstâncias excepcionais, quando, por exemplo, há distância espacial e temporal entre os interlocutores. Fiorin exemplifica esse caso com a carta, na qual a compreensão de um dêitico como hoje se dá apenas mediante sua ancoragem em uma divisão do tempo crônico, que é a data em que a carta foi escrita. Em um diálogo face a face, essa ancoragem e mesmo a utilização de um marco temporal como hoje se fazem menos necessárias. 
Mas, caso o momento de referência seja pretérito ou futuro, empregam-se os tempos verbais do sistema enuncivo, ocorrendo, então, uma "debreagem temporal enunciva". Nesse caso, o momento de referência em relação ao qual os acontecimentos são anteriores, concomitantes ou posteriores precisa ser explicitado.

$\mathrm{Na}$ distribuição dos tempos verbais entre os sistemas enunciativo e enuncivo, vale esclarecer as funções que o pretérito perfeito simples exerce em cada sistema. Ensina Fiorin que línguas como o francês, o romeno e o italiano possuem tempos verbais diferentes para expressar a anterioridade em relação ao momento de referência presente e a concomitância em relação ao momento de referência pretérito. No francês, por exemplo, essa é a diferença entre o passé composé e o passé simple (BENVENISTE, 1976; BOTH-DIEZ, 1985).

No português, o pretérito perfeito simples acumula as duas funções, o que permite ao autor dizer que, do ponto de vista funcional, o português possui dois pretéritos perfeitos: "o 1, que é tempo do sistema enunciativo, e o 2, que pertence ao sistema enuncivo" (FIORIN, 2010, p. 153). Ele observa ainda que, no português, o pretérito perfeito composto (tem lido) exerce uma função mais aspectual do que temporal, ao indicar que um acontecimento teve início antes do momento de referência presente e continua a ocorrer nesse momento.

No interior do subsistema enuncivo da anterioridade, o pretérito perfeito 2 compartilha com o imperfeito a função de expressar a concomitância do momento do acontecimento em relação ao momento de referência. Mas é preciso notar que, se esses dois tempos não se diferenciam do ponto de vista temporal, eles apresentam uma diferença importante do ponto de vista aspectual: "o pretérito perfeito 2 assinala um aspecto limitado, acabado, pontual, dinâmico, enquanto o pretérito imperfeito marca um aspecto não-limitado, inacabado, durativo, estático" (FIORIN, 2010, p. 155). Nesse sentido, a função aspectual do pretérito imperfeito é indicar uma concomitância contínua, por meio da qual se estende a duração do acontecimento. Já a função aspectual do pretérito perfeito 2 é apresentar o acontecimento como concomitante em relação ao momento de referência, desconsiderando a sua duração (VARGAS, 2011) ${ }^{4}$.

Como exposto até agora, a distribuição dos tempos verbais do português entre os sistemas enunciativo e enuncivo e, no interior deste, entre os subsistemas enuncivos da anterioridade e da posterioridade é bastante rigorosa, uma vez que cada momento de referência apresenta um tempo verbal capaz de sinalizar que o acontecimento expresso é anterior, concomitante ou posterior a esse momento. Dessa forma, a distribuição dos tempos verbais mostra que cada tempo apresenta uma função básica no discurso, que é a de indicar a concomitância, a anterioridade ou a posterioridade do acontecimento expresso pelo verbo.

Entretanto, no discurso, o enunciador pode utilizar os verbos neutralizando ou suspendendo os termos da categoria topológica concomitância vs não-concomitância (anterioridade vs posterioridade), com o objetivo de produzir determinados efeitos de sentido. Nesse caso, um tempo verbal é usado no lugar de outro. Segundo Fiorin (2010,

\footnotetext{
${ }^{4}$ Uma longa tradição de estudos da narrativa busca associar o par pretérito perfeito/pretérito imperfeito ao par primeiro plano/segundo plano ou ao par figura/fundo (CASTILHO, 1978; REINHART, 1982; WEINRICH, 1973). Nessa tradição, os acontecimentos centrais do primeiro plano seriam expressos pelo perfeito, ao passo que os acontecimentos periféricos do segundo plano seriam expressos pelo imperfeito. Essa correlação será discutida adiante, na análise das sequências narrativas.
} 
p. 191), "com esse procedimento, passa-se da ilusão enunciativa da naturalidade dos tempos do dizer e do dito, da quimera de que o tempo linguístico é o tempo do mundo para a certeza de que o tempo é efeito de sentido produzido na e pela enunciação". Por meio desse procedimento, é possível, por exemplo, presentificar o futuro ou o passado, apresentar como inevitável uma consequência futura, pôr em dúvida a veracidade de acontecimentos passados, etc.

Ainda de acordo com o autor, é possível neutralizar:

a) um tempo enunciativo e um enuncivo correspondente;

b) um termo da categoria topológica e outro, dentro do mesmo sistema ou subsistema temporal;

c) um termo da categoria topológica com outro de um sistema ou subsistema temporal distinto. (FIORIN, 2010, p. 192)

Como exemplo do primeiro caso, Fiorin cita o chamado presente histórico, em que o presente (concomitância no sistema enunciativo) é empregado no lugar do pretérito perfeito 2 (concomitância no subsistema enuncivo da anterioridade). Uma ocorrência do segundo caso é a neutralização da oposição entre a concomitância (presente) e a posterioridade (futuro do presente) do sistema enunciativo em um enunciado como Amanhã vou lá. Por fim, o terceiro caso ocorre quando se emprega, por exemplo, o futuro do pretérito (posterioridade no subsistema enuncivo da anterioridade) no lugar do presente (concomitância no sistema enunciativo), na busca por mostrar que o acontecimento expresso é hipotético ou imaginário.

Como dito anteriormente, para Fiorin, a projeção no discurso dos tempos verbais com sua função básica constitui a debreagem temporal. Com a debreagem temporal, cria-se "a impressão de estar sempre em presença de uma temporalidade nãolinguística" (p. 191). Já a utilização de tempos verbais que neutraliza termos da categoria topológica constitui a embreagem temporal. Por meio desse recurso, "o efeito de sentido que se produz é o de que o tempo é pura construção do enunciador, que presentifica o passado, torna o futuro presente, etc" (p. 191) ${ }^{5}$.

$\mathrm{Na}$ continuação deste trabalho, a proposta apresentada neste item será utilizada para compreender o modo como os jornalistas empregam as formas verbais para expressar a dinâmica temporal dos acontecimentos que representam. Inicialmente, trato do emprego das formas verbais do indicativo em sua função básica. Ou seja, analiso o emprego das formas verbais especializadas em expressar a anterioridade, a concomitância e a posterioridade do acontecimento nos sistemas enunciativo e enuncivo, estudando, assim, o que Fiorin conceitua como debreagem temporal. Essa etapa da análise se fez em dois momentos. Primeiro, verifiquei a distribuição das formas verbais empregadas nas sequências narrativas entre os sistemas enunciativo e enuncivo. Depois, verifiquei a distribuição dessas formas verbais pelos episódios constitutivos do tipo narrativo da reportagem.

\footnotetext{
${ }^{5}$ Na proposta de Fiorin, a partir de Benveniste e em consonância com postulações de Greimas, a debreagem e a embreagem são mecanismos que afetam não apenas a categoria de tempo, mas também a de pessoa e a de espaço. Para mais esclarecimentos, ver Fiorin (2010, cap. 1).
} 
Posteriormente, estudo o procedimento por meio do qual o jornalista, ao empregar as formas verbais, neutraliza termos da categoria topológica concomitância vs nãoconcomitância (anterioridade vs posterioridade), realizando o que Fiorin chama de embreagem temporal. Essa etapa da análise também se fez em dois momentos. Primeiro, investiguei a frequência das embreagens enunciativa e enunciva nas sequências narrativas. Depois, investiguei a distribuição dessas embreagens entre os episódios do tipo narrativo da reportagem.

\section{DEBREAGEM TEMPORAL}

O primeiro passo da análise consistiu em verificar como ocorre a distribuição dos tempos enunciativos e enuncivos nas sequências narrativas do gênero reportagem. $\mathrm{O}$ interesse era investigar quais e quantas formas verbais de cada sistema ocorrem no corpus. Das 53 sequências narrativas estudadas, dez são encaixadas, ou seja, dez sequências constituem um dos episódios de outra sequência narrativa, a encaixante. Por isso, para que uma mesma forma verbal não fosse computada duas vezes, foi necessário desconsiderar essas sequências encaixadas da contagem realizada nesse primeiro momento da análise. Os resultados estão na tabela 1:

\section{Tabela 1 - Frequência das formas verbais (debreagem temporal)}

\begin{tabular}{lrrlrr}
\hline \multicolumn{1}{c}{ Sistema enunciativo } & & \multicolumn{2}{c}{ Sistema enuncivo } \\
\hline \multicolumn{1}{c}{ Formas verbais } & $\mathbf{N}$ & $\mathbf{\%}$ & \multicolumn{1}{c}{ Formas verbais } & $\mathbf{N}$ & $\mathbf{\%}$ \\
Presente & 108 & 50,70 & Pretérito perfeito 2 & 110 & 70,97 \\
Pretérito perfeito 1 & 90 & 42,26 & Pretérito imperfeito & 39 & 25,17 \\
Futuro do presente & 13 & 6,10 & Pretérito mais-que-perfeito & 3 & 1,93 \\
Pretérito perfeito composto & 2 & 0,94 & Futuro do pretérito & 3 & 1,93 \\
\hline Total & $\mathbf{2 1 3}$ & $\mathbf{1 0 0}$ & Total & $\mathbf{1 5 5}$ & $\mathbf{1 0 0}$ \\
\hline
\end{tabular}

Ao contrário do que ocorre em sequências narrativas de gêneros literários, as sequências narrativas de reportagens apresentam predominância de formas verbais do sistema enunciativo. E, dessas formas, há predominância de verbos no presente $(50,70 \%)$, como ocorre também no gênero notícia $(\mathrm{KOCH}, 1997)$. A importância desse resultado está em revelar o impacto do gênero reportagem sobre o emprego das formas verbais.

Uma das demandas do leitor de reportagens é a de que o jornalista aborde acontecimentos atuais, que, de alguma forma, afetem direta ou indiretamente seu cotidiano (CUNHA, 2009). Assim, em uma reportagem, "o que eu leio é o que se espera [que] esteja ocorrendo, no momento em que leio" (MOUILLAUD, 2002, p. 176). Na busca por atender a essa demanda, o jornalista aborda principalmente acontecimentos que têm como eixo organizador o momento da enunciação, momento que corresponde à data de publicação da revista. Em outros termos, a maior parte dos acontecimentos expressos nas sequências narrativas são concomitantes (presentes), anteriores (passados) ou posteriores (futuros) ao momento de enunciação e não a um momento de referência pretérito ou futuro instalado no enunciado. 
Dessa forma, expressar acontecimentos por meio de formas verbais do sistema enunciativo é um dos recursos de que o jornalista se vale para produzir um efeito de atualidade, para convencer o leitor de que os fatos expressos têm impacto e ressonância no momento presente, como se verifica nesta sequência ${ }^{6}$ :

\section{(01)}

(01) Além disso, [a Defensoria] destaca [P/PP1] que a responsabilidade das ocupações ilegais nas margens do Tietê não devem ser atribuídas [P] apenas às comunidades pobres, (02) uma vez que o poder público disponibilizou [PP2] infraestrutura urbana, (03) como água encanada, escolas, asfaltamento e energia. (04) No Jardim Romano, por exemplo, (05) o prefeito Gilberto Kassab (DEM) inaugurou [PP1] no ano passado um Centro Educacional Unificado (CEU). (06) Na mesma rua Capachós, (07) um conjunto habitacional financiado pela Caixa Econômica Federal também foi inaugurado [PP1] recentemente. (08) Os investimentos fizeram [PP1] com que a prefeitura revisasse os valores de imóveis na região, (09) com vistas ao cálculo do IPTU de 2010. (10) A valorização chega [P] a 187\%. (11) Só que, hoje, tanto a escola como a Cohab têm [P] a entrada bloqueada pelo lodo.

Nessa sequência, que trata de inundações em São Paulo, há apenas uma forma verbal pertencente ao subsistema enuncivo da anterioridade. No ato (02), o verbo no pretérito perfeito 2 disponibilizou sinaliza a concomitância do acontecimento expresso em relação a um momento de referência pretérito implícito, tal como naquela época. As demais formas verbais expressam anterioridade (fizeram, foi inaugurado) ou concomitância (chega, tem) em relação ao momento de referência presente, momento que, no ato (11), é explicitado pelo advérbio hoje. Essa maneira de expressar os acontecimentos por meio das formas verbais faz parecer que os acontecimentos se passaram num ontem ainda muito recente ou ainda ocorrem no momento da publicação da reportagem. Auxiliando as formas verbais, expressões adverbiais como recentemente (ato 07 ), no ano passado ${ }^{7}$ (ato 05) e o hoje já mencionado contribuem para a produção desse efeito.

Quanto às formas verbais enuncivas, é interessante observar que em nenhuma das sequências houve formas que expressassem anterioridade, concomitância ou posterioridade de acontecimentos em relação a um momento de referência futuro. $\mathrm{Ou}$ seja, em nenhuma das reportagens de que as 53 sequências participam, os jornalistas narraram histórias futuras.

A explicação para isso está no próprio gênero reportagem. Uma das exigências associadas a esse gênero é a de credibilidade. Sendo assim, o jornalista precisa se mostrar como um profissional ou um prestador de serviços digno da credibilidade do leitor (CUNHA, 2009). Ora, como esclarece Fiorin (2010), o futuro, seja do presente ou do pretérito, exprime a ideia de probabilidade, de algo que, por ainda não ter se realizado, não é passível de comprovação. No jornalismo, produzir sequências narrativas sobre acontecimentos que não podem ser comprovados constitui uma ameaça

\footnotetext{
${ }^{6}$ Neste trabalho, adoto as seguintes convenções: os tempos verbais do sistema enunciativo aparecem sublinhados, enquanto os do sistema enuncivo aparecem em itálico. Diante de cada forma verbal, indico entre colchetes a abreviatura do tempo desse verbo. Na sequência, há os tempos presente (P), pretérito perfeito 1 (PP1) e pretérito perfeito 2 (PP2). A numeração indica que a sequência foi segmentada em atos, que é a unidade mínima de análise adotada pelo Modelo de Análise Modular do Discurso.

${ }^{7}$ Vale lembrar que, como a reportagem é de janeiro de 2010, a expressão no ano passado indica uma anterioridade próxima em relação ao momento presente.
} 
para a credibilidade do jornalista e do veículo de comunicação para o qual trabalha (CHARAUDEAU, 2006). Em outros termos, narrar acontecimentos futuros teria um efeito semelhante ao de narrar acontecimentos fictícios ou fazer previsões e especulações, o que não constitui uma expectativa associada ao gênero reportagem. Por essa razão, as sequências do corpus não expressam acontecimentos relacionados a momentos de referência futuros.

A mesma exigência de credibilidade também pode explicar a baixa frequência na marcação da posterioridade do acontecimento no sistema enunciativo (futuro do presente $(6,10 \%))$ e no subsistema enuncivo da anterioridade (futuro do pretérito $(1,93 \%))$. Abordar acontecimentos futuros é trazer para o discurso um elemento de probabilidade ou de incerteza, o que é arriscado para alguém que, como o jornalista, tem o compromisso de parecer objetivo e imparcial.

No subsistema enuncivo da anterioridade, a maior parte das formas verbais está no pretérito perfeito 2 (70,97\%). Em seguida, vem o pretérito imperfeito com $25,17 \%$ das ocorrências. Como foi dito, essas formas verbais não se diferenciam do ponto de vista temporal, porque ambas indicam concomitância em relação a um momento de referência pretérito. Porém, elas se distinguem do ponto de vista aspectual. $\mathrm{O}$ aspecto perfectivo e pontual do perfeito contrasta com o aspecto imperfectivo e durativo do imperfeito. Como veremos adiante, essa distinção, bem como a diferença na frequência dessas formas podem ser mais bem compreendidas com a distribuição dessas formas verbais pelos episódios do tipo narrativo.

As outras formas desse subsistema apresentam uma quantidade muito pequena de ocorrências. Foram encontrados apenas três $(1,93 \%)$ verbos no pretérito mais-queperfeito e também três $(1,93 \%)$ no futuro do pretérito. Esse resultado revela que, em sequências narrativas de reportagens, não é comum o jornalista expressar acontecimentos anteriores ou posteriores ao momento de referência pretérito. A explicação para isso está no fato de que os acontecimentos anteriores a esse momento podem ser considerados obsoletos pelo leitor, que talvez já os conheça. Dessa forma, narrá-los seria, então, contrariar a exigência de atualidade, que é característica da reportagem. Por sua vez, a narrativa de acontecimentos futuros, mesmo no subsistema enuncivo da anterioridade, poderia, como já disse, imprimir no discurso a ideia de incerteza, contrariando a exigência de credibilidade.

Depois de estudar o emprego geral das formas verbais dos sistemas enunciativo e enuncivo nas sequências, o segundo passo da análise consistiu em verificar a distribuição das formas verbais pelos episódios do tipo narrativo, a fim de investigar quais e quantas formas de cada sistema ocorrem em cada episódio. Vale esclarecer que, na primeira etapa da pesquisa relatada em Cunha (2013), etapa que estudou a forma de organização sequencial do discurso, constatei que o tipo narrativo do gênero reportagem se constitui de seis episódios: sumário ( $\mathrm{Su}$ ), estágio inicial (EI), complicação (Com), avaliação (Av), resolução (Res) e estágio final (EF) ${ }^{8}$. Nesse passo da análise, as dez sequências narrativas encaixadas, desconsideradas até o momento, são consideradas, já que também elas foram analisadas em seus episódios constituintes e ajudam, assim, a descobrir a frequência de cada forma verbal no interior de cada episódio.

\footnotetext{
${ }^{8}$ Para uma definição detalhada de cada um desses episódios, ver Cunha (2013, cap. 5). Neste trabalho, esclarecimentos sobre os episódios serão dados de modo pontual, quando se fizerem necessários.
} 
A tabela 2 apresenta a distribuição das formas verbais do sistema enunciativo.

Tabela 2 - Frequência das formas verbais do sistema enunciativo por episódio

\begin{tabular}{|c|c|c|c|c|c|c|c|c|c|}
\hline \multirow[b]{3}{*}{ Sumário } & \multicolumn{8}{|c|}{ Sistema enunciativo } & \multirow{3}{*}{$\begin{array}{r}\text { Totais } \\
41\end{array}$} \\
\hline & \multicolumn{2}{|c|}{ Presente } & \multicolumn{2}{|c|}{$\begin{array}{l}\text { Pretérito } \\
\text { perfeito } 1\end{array}$} & \multicolumn{2}{|c|}{$\begin{array}{l}\text { Futuro do } \\
\text { presente }\end{array}$} & \multicolumn{2}{|c|}{$\begin{array}{l}\text { Pretérito perf. } \\
\text { composto }\end{array}$} & \\
\hline & 23 & $56,10 \%$ & 17 & $41,46 \%$ & & 0 & 1 & $2,44 \%$ & \\
\hline Estágio inicial & 12 & $54,55 \%$ & 10 & $45,45 \%$ & & 0 & & 0 & 22 \\
\hline Complicação & 16 & $33,33 \%$ & 27 & $56,25 \%$ & 4 & $8,34 \%$ & 1 & $2,08 \%$ & 48 \\
\hline Resolução & 10 & $27,78 \%$ & 24 & $66,67 \%$ & 2 & $5,55 \%$ & & 0 & 36 \\
\hline Avaliação & 42 & $67,74 \%$ & 13 & $20,97 \%$ & 7 & $11,29 \%$ & & 0 & 62 \\
\hline Estágio final & 11 & $64,71 \%$ & 6 & $35,29 \%$ & & 0 & & 0 & 17 \\
\hline
\end{tabular}

Todos os episódios apresentam uma porcentagem alta de formas verbais no presente. Mas o episódio que apresenta uma maior concentração de verbos no presente é a avaliação. Nesse episódio, $67,44 \%$ dos verbos estão nesse tempo. Isso se explica pela natureza do episódio, o qual é especializado em apresentar o ponto de vista do jornalista ou de personagens do mundo representado. Ao apresentar seu ponto de vista, um personagem, seja o jornalista, seja um especialista ou uma testemunha, expressa opiniões, esclarecimentos ou reclamações que são concomitantes ao momento de referência presente em que fala. Em uma das sequências, ao dizer "Queremos que o Exército pague os remédios dele", a mãe de um jovem torturado por militares expressa um desejo que é concomitante ao momento presente em que fala ao jornalista.

Já os episódios centrais do tipo narrativo, a complicação e a resolução, são os que apresentam uma menor taxa de verbos no presente $(33,33 \%$ e $27,78 \%$, respectivamente) e uma taxa maior de verbos no pretérito perfeito 1 (56,25\% e 66,67\%, respectivamente). Esse resultado se deve ao fato de que nesses episódios o jornalista apresenta o acontecimento que, ocorrido no espaço social, pode afetar mais diretamente o leitor, despertando seu interesse, e o resultado ou a consequência desse acontecimento. Assim, era de se esperar que o jornalista trouxesse nesses episódios uma maior quantidade de acontecimentos anteriores e não concomitantes ao momento de referência presente.

Quanto ao futuro do presente, a ideia de probabilidade inerente a essa forma verbal explica por que a maior parte de suas ocorrências se encontra na avaliação.

A tabela 3, mais adiante, expõe os resultados da distribuição das formas verbais do sistema enuncivo pelos episódios do tipo narrativo. Nesta tabela, interessa particularmente a distribuição pelos episódios das formas verbais no pretérito perfeito 2 e no pretérito imperfeito, porque foram essas as formas verbais mais frequentes. Em todos os episódios, o perfeito 2 predomina em relação ao imperfeito. Apenas no estágio inicial, essa predominância não se verifica.

Vários estudiosos estabelecem uma correlação entre, de um lado, o perfeito e o primeiro plano (figura) da narrativa e, de outro, o imperfeito e o segundo plano (fundo) (CASTILHO, 1978, 2002; COMBETTES, 1987; REINHART, 1984; RODRIGUES et al, 2002; WEINRICH, 1973). Para esses estudiosos, o perfeito seria uma marca do primeiro plano, ao expressar acontecimentos dinâmicos e pontuais. Por sua vez, o imperfeito seria uma marca do segundo plano, ao apresentar acontecimentos inacabados, estáticos e mais duradouros. 
Tabela 3 - Frequência das formas verbais do sistema enuncivo por episódio

\begin{tabular}{|c|c|c|c|c|c|c|c|c|c|}
\hline \multirow[b]{3}{*}{ Sumário } & \multicolumn{8}{|c|}{ Sistema enuncivo } & \multirow{3}{*}{$\begin{array}{r}\text { Totais } \\
6 \\
6\end{array}$} \\
\hline & \multicolumn{2}{|c|}{$\begin{array}{l}\text { Pretérito } \\
\text { perfeito } 2\end{array}$} & \multicolumn{2}{|c|}{$\begin{array}{l}\text { Pretérito } \\
\text { imperfeito }\end{array}$} & \multicolumn{2}{|c|}{$\begin{array}{l}\text { Pretérito mais-que- } \\
\text { perfeito (simples e } \\
\text { composto) }\end{array}$} & \multicolumn{2}{|c|}{$\begin{array}{l}\text { Futuro do } \\
\text { pretérito (simples } \\
\text { e composto) }\end{array}$} & \\
\hline & 6 & $100 \%$ & & 0 & & 0 & & 0 & \\
\hline $\begin{array}{l}\text { Estágio } \\
\text { inicial }\end{array}$ & 16 & $41,02 \%$ & 21 & $53,85 \%$ & 2 & $5,13 \%$ & & 0 & 39 \\
\hline Complicação & 58 & $69,88 \%$ & 21 & $25,30 \%$ & & 0 & 4 & $4,82 \%$ & 83 \\
\hline Resolução & 27 & $77,14 \%$ & 7 & $20,00 \%$ & 1 & $2,86 \%$ & & 0 & 35 \\
\hline Avaliação & 21 & $80,77 \%$ & 4 & $15,38 \%$ & & 0 & 1 & $3,85 \%$ & 26 \\
\hline Estágio final & 4 & $80,00 \%$ & 1 & $20,00 \%$ & & 0 & & 0 & 5 \\
\hline
\end{tabular}

Sem desconsiderar a validade geral dessa correlação, é preciso salientar, no entanto, que a percepção de um primeiro e de um segundo planos narrativos se liga não só a elementos sintáticos ou lexicais, mas também a fatores textuais e situacionais. Isso porque, como esclarece Bronckart (2007), acontecimentos aparentemente secundários e processos estáticos e de caráter descritivo, frequentemente no imperfeito, podem ser alçados ao primeiro plano, dependendo das decisões tomadas pelo produtor do texto e, acrescento, do gênero a que esse texto pertence.

Em outros termos e em consonância com Bronckart, considero que não se deve associar de forma rígida e sistemática o perfeito ao primeiro plano e o imperfeito ao segundo. Afinal, os episódios que compõem o segundo plano da narrativa de reportagens (sumário, estágio inicial e avaliação) deveriam apresentar predomínio de verbos no imperfeito, o que, como mostra a tabela 3, só ocorre no estágio inicial. É de se notar, inclusive, que o sumário não apresenta nenhuma ocorrência de verbos no imperfeito, embora seja considerado por alguns estudiosos um episódio do segundo plano.

Dessa forma, no estudo das sequências narrativas de reportagens, a distinção aspectual entre perfeito e imperfeito mostra-se pouco pertinente para distinguir o primeiro e o segundo planos da narrativa. Com base nos resultados da tabela 3, essa distinção parece ser mais relevante para a caracterização do sumário, que não apresentou nenhuma ocorrência do pretérito imperfeito, e do estágio inicial, que foi o único episódio em que o imperfeito superou o perfeito 2 em número de ocorrências.

No interior dos outros episódios, o imperfeito convive com os demais tempos e, por sua propriedade aspectual, atua muitas vezes no estabelecimento de um contraste local entre uma situação menos dinâmica, expressa pelo imperfeito, e um acontecimento mais dinâmico e pontual, expresso por outros tempos verbais ${ }^{9}$. É o que ocorre neste trecho da complicação de uma sequência que trata da queda de uma ponte: "Entre vinte e trinta pessoas estavam sobre a estrutura de 132 metros que desabou". A situação expressa pelo imperfeito (estavam) constitui um pano de fundo em que o acontecimento expresso pelo perfeito 2 (desabou) ganha destaque.

\footnotetext{
${ }^{9}$ O papel do imperfeito no estabelecimento de um contraste com outras formas verbais é indicado por Weinrich (1973) e Bronckart (2007).
} 
As diferenças entre os resultados apresentados aqui e os de trabalhos sobre narrativas de outros gêneros, sobretudo literários, apontam para a importância de se estudarem as especificidades das sequências narrativas produzidas em cada gênero e, consequentemente, de se evitar estender ao tipo narrativo de modo geral observações feitas com a análise de narrativas pertencentes a apenas um gênero.

\section{EMBREAGEM TEMPORAL}

Após verificar o emprego das formas verbais dos sistemas enunciativo e enuncivo com seu valor básico, a análise das sequências prosseguiu com o estudo da embreagem temporal. Como exposto, esse procedimento consiste em utilizar um tempo verbal no lugar de outro, neutralizando termos da categoria topológica concomitância vs nãoconcomitância (anterioridade vs posterioridade), com o fim de produzir determinado efeito de sentido. A análise revelou que a embreagem não constitui um procedimento frequente nas sequências narrativas da reportagem. Com efeito, foram identificadas apenas 33 embreagens enunciativas e 14 enuncivas. Nessa contagem, as sequências narrativas encaixadas foram desconsideradas, para que uma mesma forma verbal não fosse contada duas vezes. A tabela 4 apresenta as embreagens enunciativas ${ }^{10}$.

Tabela 4 - Frequência das formas verbais (embreagem enunciativa)

\begin{tabular}{lrr}
\hline & Sistema enunciativo & \\
\hline Formas verbais & $\mathbf{N}$ & $\mathbf{\%}$ \\
\hline P/PP1 & 23 & 69,70 \\
P/FPs & 6 & 18,18 \\
P/PP2 & 2 & 6,06 \\
P/FPt & 1 & 3,03 \\
P/PI & 1 & 3,03 \\
\hline Total & 33 & 100 \\
\hline
\end{tabular}

Em todas as embreagens enunciativas, o resultado da neutralização é uma forma verbal no presente. De modo geral, em todas essas neutralizações enunciativas, o efeito que se obtém é o de presentificar acontecimentos anteriores ou posteriores em relação a momentos de referência presentes ou pretéritos, conferindo a esses acontecimentos a certeza e a atualidade do presente. Vejamos este exemplo:

(07) De uniforme azul, (08) o cabisbaixo pedreiro Crispim Antonio de Souza, de 50 anos, lamenta [P/PP1]: (09) "Hoje derrubo [P] a casa dos outros. (10) Amanhã pode ser [P/FPs] a minha".

\footnotetext{
${ }^{10}$ Indicando as neutralizações, a abreviatura da forma verbal empregada é seguida pela abreviatura da forma verbal substituída. Nessa tabela, as abreviaturas correspondem às seguintes formas verbais: futuro do presente $(\mathrm{FPs})$, futuro do pretérito $(\mathrm{FPt})$, presente $(\mathrm{P})$, pretérito imperfeito $(\mathrm{PI})$, pretérito perfeito 1 (PP1), pretérito perfeito 2 (PP2).
} 
Nesse trecho, há duas embreagens. No ato (08), o lamento feito por Crispim é anterior ao momento de referência presente. No sistema enunciativo, a anterioridade é expressa pelo pretérito perfeito 1 (lamentou) e não pelo presente (lamenta). Ao suspender a oposição anterioridade-concomitância no sistema enunciativo, o jornalista presentifica um acontecimento passado, fazendo parecer que a fala da testemunha é concomitante ao momento de referência presente.

Essa presentificação de ações linguageiras (lamentar, dizer, afirmar) ocorridas antes do momento de referência presente é o tipo de embreagem mais comum no corpus. Com essa embreagem, o jornalista cria o efeito de que o testemunho de um especialista, de um cidadão ou de um político, tomado evidentemente antes da data de publicação da revista (momento da enunciação), se produz nesse mesmo momento, o que contribui para gerar o efeito de atualidade da reportagem.

No ato (10) do trecho acima, ocorre a segunda embreagem mencionada. O advérbio amanhã indica que a ação de Crispim de derrubar sua própria casa poderá ocorrer no futuro. No sistema enunciativo, a posterioridade é expressa pelo futuro do presente (poderá) e não pelo presente (pode). Mas, neutralizando os termos posterioridade-concomitância, o personagem expressa a certeza da ação futura ${ }^{11}$.

Já as embreagens enuncivas ocorrem em menor quantidade, mas são mais variadas, já que o resultado da neutralização não é apenas um tempo verbal. É o que se verifica na tabela $5^{12}$.

\section{Tabela 5 - Frequência das formas verbais (embreagem enunciva)}

\begin{tabular}{lrr}
\hline & Sistema enuncivo & \\
\hline Formas verbais & $\mathrm{N}$ & $\%$ \\
\hline PI/P & 4 & 28,57 \\
PI/PP1 & 3 & 21,43 \\
PI/FPt & 2 & 14,29 \\
PMPC/PP1 & 2 & 14,29 \\
FPtC/PP2 & 1 & 7,14 \\
FPt/P & 1 & 7,14 \\
PMP/FPt & 1 & 7,14 \\
\hline Total & 14 & 100 \\
\hline
\end{tabular}

Nas embreagens enuncivas identificadas no corpus, o resultado são formas verbais no pretérito imperfeito, no pretérito mais-que-perfeito simples e composto e no futuro do pretérito simples e composto.

Nas embreagens em que o imperfeito (concomitância no subsistema enuncivo da anterioridade) substitui o presente (concomitância no sistema enunciativo), cria-se um efeito de sentido de irrealidade ou de que os acontecimentos são hipotéticos (FIORIN, 2010, p 208-209), como neste trecho:

\footnotetext{
${ }^{11}$ Nesse trecho, essa certeza é atenuada pelo verbo auxiliar modal pode.

${ }^{12} \mathrm{Na}$ tabela, as abreviaturas correspondem a estas formas verbais: futuro do pretérito (FPt), futuro do pretérito composto (FPtC), presente (P), pretérito imperfeito (PI), pretérito-mais-que-perfeito (PMP), pretérito-mais-que-perfeito composto (PMPC), pretérito perfeito 1 (PP1), pretérito perfeito 2 (PP2).
} 
(03)

(06) Nos últimos anos, porém, (07) as praias cariocas tornaram-se [PP1] lugares quase intransitáveis. (08) Não apenas porque há $[\mathrm{P}]$ mais gente. (09) O maior tumulto é $[\mathrm{P}]$ provocado pela turba de barraqueiros, camelôs e flanelinhas que tomou [PP1] conta do pedaço. (10) A ideia de que a orla do Rio era [PI/P] um espaço de convivência extremamente democrático serviu [PP1] apenas como pretexto para a falta de organização.

(11) A baderna se espalhou [PP1].

No ato (10), a ideia de que a orla das praias é um espaço de convivência democrático prevalece no momento de referência presente, já que ainda nesse momento "há mais gente nas praias" e não houve menção por parte do jornalista de tomada de medida que mudasse a situação. Entretanto, ao empregar era para sinalizar a concomitância com o momento presente, o jornalista cria o efeito de sentido de que essa ideia da democracia das praias cariocas é uma hipótese.

Nas embreagens em que o imperfeito substitui o futuro do pretérito (posterioridade no subsistema enuncivo da anterioridade), o efeito de sentido que se produz é outro. Agora o efeito é o de apresentar como inevitável um acontecimento previsto para o futuro (FIORIN, 2010, p. 202-203).

(01) Poucas horas depois, (02) as redes de tevê escancaravam [PI/FPt] para todo o Brasil que o absurdo da tortura não foi [PP1] uma exclusividade da ditadura e que suas vítimas não se resumem $[\mathrm{P}]$ à elite intelectual e política que hoje está $[\mathrm{P}]$ no poder.

A expressão Poucas horas depois indica a posterioridade do acontecimento escancarar em relação a um momento de referência pretérito mencionado no cotexto, que é o momento de uma reunião entre o então presidente Lula e ministros. No trecho acima, o jornalista expressa essa posterioridade com o pretérito imperfeito (escancaravam) e não com o futuro do pretérito (escancarariam), indicando a certeza e a inevitabilidade do acontecimento futuro.

Nas embreagens em que o imperfeito substitui o pretérito perfeito 1 (anterioridade no sistema enunciativo), estende-se a duração dos acontecimentos, o que permite mostrar que acontecimentos anteriores ao momento de referência presente foram percebidos como estáticos, duradouros e inacabados.

(27) Na semana passada, (28) cinco dias depois do temporal, (29) São Luiz ainda era [PI/PP1] só escombros. (30) Bujões de gás podiam ser [PI/PP1] vistos em cima de telhados

(31) e carros se equilibravam [PI/PP1] por sobre os pedaços que haviam restado [PMPC/PP1] da igreja matriz (...).

A expressão na semana passada indica anterioridade em relação ao momento de referência presente, mas os verbos não estão no pretérito perfeito 1 e sim no imperfeito. Essa embreagem permite ao jornalista oferecer uma descrição de como ficou a cidade de São Luiz do Paraitinga após um forte temporal. 
Nas embreagens em que o pretérito mais-que-perfeito (anterioridade no subsistema enuncivo da anterioridade) é empregado no lugar do pretérito perfeito 1 (anterioridade no sistema enunciativo), cria-se o efeito de que o acontecimento é ainda mais anterior em relação ao momento de referência presente (FIORIN, 2010, p. 211).

\begin{abstract}
(06)
(01) O som estridente da marreta contra a coluna de concreto ecoa [P/PP1] pela ladeira dos Peixes, na Vila Aimoré, zona leste de São Paulo. (02) Ao redor dos trabalhadores, (03) um cenário de destruição. (04) Ao menos uma dezena de casas já havia sido demolida [PMPC/PP1] por ordem da prefeitura, (05) após a remoção das famílias que concordaram [PP1] em receber um auxílio aluguel de 300 reais para abandonar a várzea do rio Tietê, (06) severamente castigada pela megaenchente de 8 de dezembro.
\end{abstract}

Embora a remoção das famílias (ato 05) seja posterior à demolição das casas (ato 06), a ação de demolir é expressa pelo pretérito mais-que-perfeito (havia sido demolida) e não pelo pretérito perfeito 1 ( foi demolida). Mas com o mais-que-perfeito o jornalista cria o efeito de sentido de que, em relação ao momento de referência presente, a demolição das casas é um acontecimento mais distante (e menos relevante) do que a remoção das famílias.

Já nas embreagens em que o pretérito mais-que-perfeito substitui o futuro do pretérito (posterioridade no subsistema enuncivo da anterioridade), apresenta-se como acabado um acontecimento futuro, o qual, dessa forma, é visto como inevitável (FIORIN, 2010, p. 205).

(12) Segundo testemunhas, (13) cinco funcionários da instituição, tendo à frente o agente Wilson Santos, submeteram [PP2] Andreu a uma bárbara sessão de espancamento. (14) "Quebraram [PP2] cabos de vassoura (15) para furar o corpo dele, (16) jogaram [PP2] cadeiras, mesas e uma lata de lixo em cima do garoto", (17) relata [P/PP1] a mãe, Deize Silva de Carvalho, 38 anos. (18) "As testemunhas dizem [P/PP1] que eles encheram [PP2] sacos com cascas de coco vazio (19) e bateram [PP2] na cabeça do meu filho com eles." (20) O laudo do hospital para onde fora levado [PMP/FPt] atestou [PP2] "agressão física" (21) e também o laudo da perícia apontou [PP2] vários indícios de agressão.

A tortura sofrida por Andreu é concomitante ao momento de referência pretérito no primeiro dia de 2008, mencionado no cotexto. Em relação a esse momento, os acontecimentos relatados pela mãe são concomitantes, o que é indicado pelos verbos no pretérito perfeito 2. Em relação ao momento da tortura, a ida de Andreu ao hospital (ato 20) é posterior e não anterior, já que os ferimentos decorrentes da tortura são a causa da ida ao hospital. Porém, na sequência, essa posterioridade é expressa pelo mais-queperfeito (fora levado) e não pelo futuro do pretérito (seria levado). Ao suspender a oposição anterioridade-posterioridade, o jornalista consegue indicar que a internação de Andreu em um hospital, após a tortura por ele sofrida no Departamento-Geral de Ações Socioeducativas, era inevitável.

Por fim, nas embreagens em que o futuro do pretérito (posterioridade no subsistema enuncivo da anterioridade) substitui o pretérito perfeito 2 (concomitância no 
subsistema enuncivo da anterioridade) ou o presente (concomitância no sistema enunciativo), o jornalista cria o efeito de sentido de incerteza, contribuindo para modalizar o seu discurso ${ }^{13}$. Por meio dessas embreagens, "O enunciador deixa claro, então, que, de seu ponto de vista, o acontecimento não está confirmado e demanda comprovação" (FIORIN, 2010, p. 204). As duas embreagens identificadas no corpus em que o futuro do pretérito substitui o pretérito perfeito 2 e o presente estão neste trecho:

\section{(08)}

(06) A informação [de que o governo de são Paulo fechou seis comportas de uma barragem] levou [PP1] o promotor de Justiça Eduardo Valerio a instaurar um inquérito para apurar se o fechamento da barragem poderia ter causado [FPtC/PP2] a inundação da zona leste. (07) "Ainda estamos investigando [P], (08) mas aparentemente este incidente não seria $[\mathrm{FPt} / \mathrm{P}]$ o suficiente para alagar toda a região, (09) já que é $[\mathrm{P}]$ um procedimento de rotina, realizado mais de 30 vezes em 2009", (10) afirma [P/PP1] Valerio.

No ato (06), o fechamento da barragem é um acontecimento concomitante em relação ao momento de referência mencionado no cotexto na madrugada da enchente. Mas essa concomitância é expressa pelo futuro do pretérito (poderia ter causado) e não pelo pretérito perfeito 2 (causou). Procedendo dessa forma, o jornalista revela que não tem certeza sobre as causas da inundação e que a investigação ainda está em curso, como indicado na fala do promotor: "Ainda estamos investigando".

No ato (08) dessa sequência, a impossibilidade de o fechamento das comportas inundar uma dada região é um fato concomitante em relação ao momento de referência presente, o qual corresponde ao momento em que o promotor faz a declaração ao jornalista. Essa concomitância é semelhante à expressa pelo presente em descrições de estados considerados imutáveis, tal como "O rio Tietê passa por São Paulo" "14. Mas, na sequência, o promotor sinaliza essa concomitância não com o presente (é), mas como o futuro do pretérito (seria), o que permite a ele não se comprometer com a veracidade da informação, já que a investigação ainda estava em curso.

O último passo da análise das formas verbais das sequências narrativas do corpus consistiu em verificar a distribuição das embreagens temporais pelos episódios do tipo narrativo. Vale esclarecer, no entanto, que os resultados alcançados nessa etapa final são muito pouco elucidativos, tendo em vista o número bastante reduzido de embreagens identificadas. Como as dez sequências encaixadas também foram estudadas em seus episódios constitutivos, elas foram consideradas nesse momento da análise.

Os resultados expostos na tabela 6 são relevantes não porque sejam conclusivos (pois não o são), mas porque permitem levantar algumas hipóteses para estudos futuros sobre a distribuição dos tipos de embreagens pelos episódios do tipo narrativo.

\footnotetext{
${ }^{13} \mathrm{O}$ emprego do futuro do pretérito como recursos de modalização no jornalismo impresso é estudado por Sullet-Nylander (2006). Travaglia (1999) verifica o papel dessa forma verbal como recurso de modalização em textos orais formais.

${ }^{14}$ Esse exemplo foi extraído de Fiorin (2010, p. 151).
} 
Tabela 6 - Frequência das formas verbais por episódio

\begin{tabular}{lrrrrrr}
\hline & \multicolumn{7}{c}{ Sistema enunciativo } & & & \\
\hline & P/PP1 & P/FPs & P/PP2 & P/FPt & P/PI & Totais \\
\hline $\mathrm{Su}$ & $2(100 \%)$ & 0 & 0 & 0 & 0 & 2 \\
$\mathrm{EI}$ & 0 & 0 & 0 & 0 & 0 & 0 \\
$\mathrm{Com}$ & $4(57,14 \%)$ & $3(42,86 \%)$ & 0 & 0 & 0 & 7 \\
$\mathrm{Av}$ & $21(84 \%)$ & $3(12 \%)$ & $1(4 \%)$ & 0 & 0 & 25 \\
$\mathrm{Res}$ & $1(25 \%)$ & 0 & $1(25 \%)$ & $1(25 \%)$ & $1(25 \%)$ & 4 \\
$\mathrm{EF}$ & 0 & 0 & 0 & 0 & 0 & 0 \\
\hline
\end{tabular}

Sistema enuncivo

\begin{tabular}{lrrrrrrrr}
\hline & PMPC/PP1 & \multicolumn{1}{c}{$\mathrm{PI} / \mathrm{P}$} & $\mathrm{FPtC} / \mathrm{PP} 2$ & $\mathrm{FPt} / \mathrm{P}$ & $\mathrm{PI} / \mathrm{FPt}$ & $\mathrm{PMP} / \mathrm{FPt}$ & $\mathrm{PI} / \mathrm{PP} 1$ & Totais \\
\hline Su & 0 & 0 & 0 & 0 & $1(100 \%)$ & 0 & 0 & 1 \\
EI & 0 & $2(100 \%)$ & 0 & 0 & 0 & 0 & 0 & 2 \\
Com & $1(100 \%)$ & 0 & 0 & 0 & 0 & 0 & 0 & 1 \\
Av & 0 & $2(50 \%)$ & 0 & 1 & $1(25 \%)$ & 0 & 0 & 4 \\
& & & & $(25 \%)$ & & & & \\
Res & 0 & 0 & $1(50 \%)$ & 0 & 0 & $1(50 \%)$ & 0 & 2 \\
EF & $2(33,34 \%)$ & $1(16,66 \%)$ & 0 & 0 & 0 & 0 & $3(50 \%)$ & 6 \\
\hline
\end{tabular}

Assim, a avaliação é o episódio que apresenta um maior número de embreagens enunciativas. Em hipótese, isso se explica pelo fato de que, sendo a avaliação especializada em apresentar o ponto de vista ou a opinião de um personagem, os acontecimentos desse episódio costumam ter como eixo ordenador o eu, o aqui e o agora da enunciação. Não por acaso, a avaliação é o episódio que apresenta maior frequência de verbos no presente (tabela 2). Sendo assim, pode ser uma característica desse episódio neutralizar os termos da categoria topológica concomitância vs nãoconcomitância (anterioridade vs posterioridade), em favor da concomitância em relação ao momento de referência presente.

A tabela 6 mostra também que a maior parte das ocorrências da embreagem presente/pretérito perfeito 1 se concentrou na avaliação e que não houve nenhuma ocorrência dessa mesma embreagem nos episódios estágio inicial e estágio final. Esse resultado parece constituir um indício de que determinados tipos de embreagens ocorrem preferencialmente em alguns episódios.

Por fim, a maior parte dos episódios apresenta tanto embreagens enuncivas quanto embreagens enunciativas. Apenas o estágio inicial e o estágio final não apresentaram nenhuma embreagem enunciativa, o que parece se dever exclusivamente à extensão reduzida do corpus analisado. Isso mostra não ser possível estabelecer uma correlação entre tipos de embreagem (enunciva ou enunciativa) e os episódios do tipo narrativo.

\section{CONSIDERAÇÕES FINAIS}

Apresentando parte dos resultados obtidos em Cunha (2013), este trabalho procurou evidenciar como os jornalistas, ao construírem sequências narrativas no interior de reportagens, utilizam as formas verbais do indicativo. Com base na proposta de Fiorin, realizou-se o estudo das formas verbais presentes em 53 sequências extraídas de reportagens publicadas nas revistas semanais de informação Carta Capital, Época, 
IstoÉ e Veja. A análise permitiu constatar a complexidade da maneira como os jornalistas usam as formas verbais para expressar a dinâmica temporal dos acontecimentos, bem como a profunda relação que se estabelece entre o emprego das formas verbais e o gênero do discurso.

$\mathrm{Na}$ interação que se estabelece entre jornalista e leitor por meio de uma reportagem, uma das demandas do leitor é a de que o jornalista aborde acontecimentos atuais, que, de alguma forma, afetem direta ou indiretamente seu cotidiano. Os resultados da análise das formas verbais mostraram que, como consequência dessa demanda, a maior parte dos acontecimentos expressos nas sequências tem como eixo organizador o momento da enunciação, momento que corresponde à data de publicação da revista, e não um momento de referência pretérito ou futuro instalado no enunciado.

Assim, a predominância de formas verbais do sistema enunciativo e, especificamente, de verbos no presente é um dos recursos de que o jornalista se vale para produzir um efeito de atualidade, para convencer o leitor de que os fatos expressos têm impacto e ressonância no momento presente. Considerando a distribuição das formas verbais pelos episódios do tipo narrativo, a análise permitiu constatar que todos eles apresentam alto índice de formas verbais no presente, mas que a avaliação é o episódio que apresenta maior concentração de verbos nessa forma.

Quanto às embreagens, as sequências narrativas de reportagens costumam apresentar maior número de embreagens enunciativas, tendo como resultado uma forma verbal no presente, o que também tem como finalidade fazer o leitor crer que o jornalista sempre expressa fatos bastante atuais.

Como exposto na introdução deste trabalho, o estudo das formas verbais em sequências narrativas de reportagens se fez na segunda etapa da pesquisa apresentada em Cunha (2013), etapa que estudou a forma de organização composicional do discurso. $\mathrm{Na}$ terceira etapa da pesquisa, a que estudou a forma de organização estratégica, a análise da dinâmica temporal das sequências foi combinada com a análise de outros planos do discurso. Por meio dessa combinação, foi possível constatar que as formas verbais, bem como outras marcas da dimensão linguística, funcionam como estratégias discursivas que auxiliam o jornalista, na interação que estabelece com os leitores, a preservar sua face (autoimagem) e seu território (domínio privado), preservar ou agredir a face do outro, dominá-lo, colocando-se num lugar elevado, ou se deixar dominar, permitindo ao outro que se sobreponha na interação.

\section{REFERÊNCIAS}

BENVENISTE, E. As relações de tempo no verbo francês. In: São Paulo: Ed. Nacional, Ed. Universidade de São Paulo, 1976, p. 260-276. . Problemas de linguística geral.

BOTH-DIEZ, A. M. L'aspect et ses implications dans le fonctionnement de l'imparfait, du passé simple et du passé composé au niveau textuel. Langue Française, n. 67, p. 5-22, 1985.

BRONCKART, J. P. Atividade de linguagem textos e discursos: por um interacionismo sócio-discursivo. São Paulo: EDUC, 2007.

CASTILHO, A. T. A dimensão textual do verbo. Estudos Linguísticos, n. 2, p. 125-140, 1978. Aspecto verbal no português falado. In: ABAURRE, M. B. M.; RODRIGUES, A. C. S. (Orgs.)

Gramática do português falado: novos estudos descritivos. v. 8, 2002, p. 83-112. 
CHARAUDEAU, p. Discurso das mídias. São Paulo: Contexto, 2006.

COMBETTES, B. Types de textes et faits de langue. Pratiques, n. 56, p. 5-17, 1987.

CUNHA, G. X. O impacto do contexto na construção da narrativa em uma reportagem do jornalismo político. In: NETO, F. K.; RUFINO, J. A.; BAPTISTA, M. R. (Orgs.) Espaços, sujeitos e sociedade: diálogos. Barbacena: EdUEMG, 2009, p. 81-95.

A articulação discursiva do gênero artigo de opinião à luz de um modelo modular de análise do discurso. Filologia e Linguística Portuguesa, v. 14, p. 73-97, 2012.

A construção da narrativa em reportagens. 2013. 601f. Tese (Doutorado em Linguística) Faculdade de Letras, Universidade Federal de Minas Gerais, Belo Horizonte, 2013.

FILLIETTAZ, L. Une approche modulaire de l'hétérogénéité compositionnelle du discours: le cas des récits oraux. Cahiers de linguistique française, v. 21, p. 261-327, 1999.

FILLIETTAZ, L.; GROBET, A. L'hétérogénéité compositionnelle du discours: quelques remarques préliminaires. Cahiers de linguistique française, v. 21, p. 213-259, 1999.

FIORIN, J. L. As astúcias da enunciação: as categorias de pessoa, espaço e tempo. São Paulo: Ática, 2010 .

Pragmática. In: Contexto, 2011, p. 161-186. . (Org.) Introdução à Linguística: princípios de análise. v. 2. São Paulo:

KOCH, I. G. V. A inter-ação pela linguagem. São Paulo: Contexto, 1997.

MARINHO, J. H. C. Uma abordagem modular e interacionista da organização do discurso. Revista da Anpoll, v. 16. p. 75-100. 2004.

MARINHO, J. H. C.; CUNHA, G. X. A construção da cadeia referencial em textos de estudantes universitários. Alfa, v. 58, n. 1, p. 11-33, 2014

MOUILLAUD, M. Posturas do leitor. In: PORTO, S. D. (Org.) O Jornal: da forma ao sentido. Brasília: Editora Universidade de Brasília, 2002, p. 173-190.

REINHART, T. Principles of gestalt perception in the temporal organization of narrative texts. Linguistics, v. 22, p. 779-809, 1984.

RODRIGUES, A. C. S. et al. Formas de pretérito perfeito e imperfeito do indicativo no plano textualdiscursivo. In: KOCH, I. G. V. (Org.) Gramática do português falado: desenvolvimentos. v. 6, 2002, p. 417-462.

ROULET, E.; FILLIETTAZ, L.; GROBET, A. Un modèle et un instrument d'analyse de l'organisation du discours. Berne: Lang, 2001.

SULLET-NYLANDER, F. Paratexte, contexte et intertexte dans Le Monde (2005): conditionnels journalistiques et discours rapportés. Pratiques, n. 129/130, p. 123-138, 2006.

TRAVAGLIA, L. C. O uso do futuro do pretérito no português falado. In: NEVES, M. H. M. (Org.) Gramática do português falado: novos estudos. v. 7, 1999, p. 673-700.

VARGAS, M. V. Verbo e práticas discursivas. São Paulo: Contexto, 2011.

WEINRICH, H. Le temps. Paris: Éditions du Seuil, 1973.

\section{Recebido em: 19/07/13. Aprovado em: 03/01/14.}

Title: The construction of temporal dynamic in journalism: analysis of the use of verbal forms in narrative sequences in news reports

Author: Gustavo Ximenes Cunha

Abstract: This paper makes a partial presentation of the results of the research developed in Cunha (2013), in order to evince how journalists use verbal forms to build the temporal dynamic in narrative sequences in their texts. In order to carry out an adequate study of the verbal forms in Portuguese, this research resorted to Fiorin's (2010, 2011) proposition as an analytical tool to study the regularities and the specificities of the verbal forms used in the 53 narrative sequences of the corpus. The analyses put in evidence the complex use of verbal forms by journalists to express the temporal dynamic of the events narrated, as well as the deep relation between verbal forms and the discourse genre.

Keywords: Narrative sequence. Verbal form. News reports. 
Título: Construcción de la dinámica temporal en periodismo: análisis del empleo de las formas verbales en secuencias narrativas de reportajes

Autor: Gustavo Ximenes Cunha

Resumen: Ese trabajo presenta parte de los resultados de una investigación desarrollada en Cunha (2013), con el objetivo de evidenciar como los periodistas utilizan las formas verbales para construir la dinámica temporal en secuencias narrativas en el interior de reportajes. Para proceder un estudio adecuado de las formas verbales del portugués, la investigación buscó, en la propuesta de Fiorin (2010, 2011), instrumentos de análisis para estudiar las regularidades y las especificidades de las formas verbales utilizadas en 53 secuencias narrativas del corpus. El análisis permitió constatar la complejidad de la manera como los periodistas usan las formas verbales para expresar la dinámica temporal de los acontecimientos, así como la profunda relación que se establece entre el empleo de las formas verbales y el género del discurso.

Palabras-clave: Secuencia narrativa. Forma verbal. Reportaje. 